\title{
MRI-guided percutaneous thermoablation in combination with hepatic resection as parenchyma-sparing approach in patients with primary and secondary hepatic malignancies: single center long-term experience
}

Moritz T. Winkelmann ${ }^{1 *}$, Rami Archid², Georg Gohla', Gerald Hefferman ${ }^{1,3}$, Jens Kübler ${ }^{1}$, Jakob Weiss ${ }^{1}$, Stephan Clasen ${ }^{1}$, Konstantin Nikolaou', Silvio Nadalin ${ }^{2}$ and Rüdiger Hoffmann ${ }^{1}$

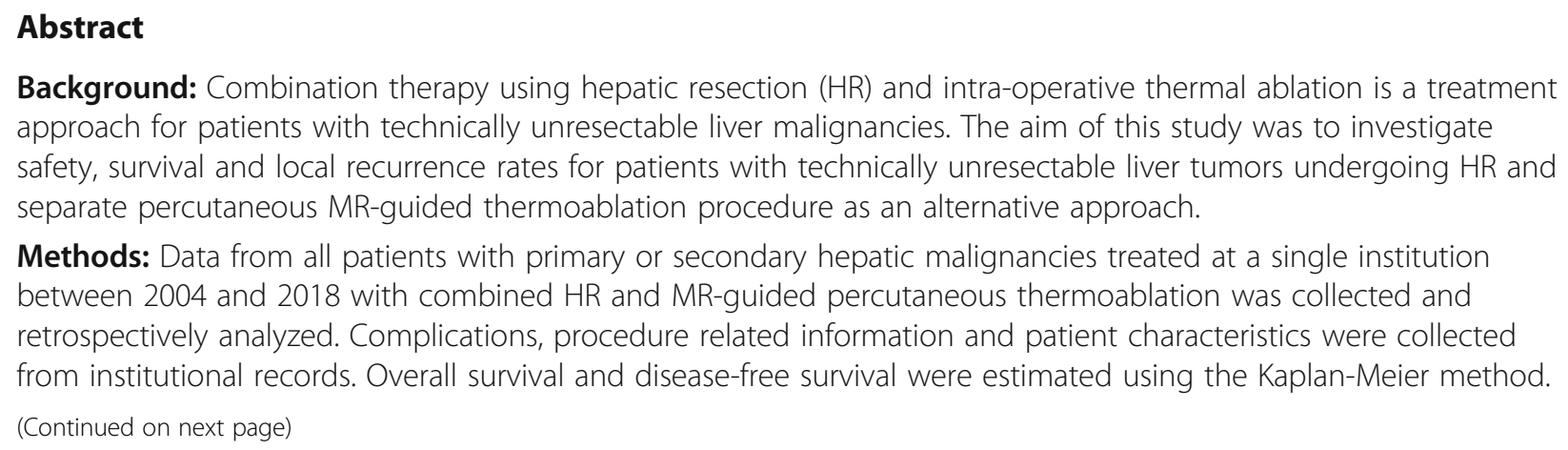
approach for patients with technically unresectable liver malignancies. The aim of this study was to investigate safety, survival and local recurrence rates for patients with technically unresectable liver tumors undergoing HR and separate percutaneous MR-guided thermoablation procedure as an alternative approach.

Methods: Data from all patients with primary or secondary hepatic malignancies treated at a single institution between 2004 and 2018 with combined HR and MR-guided percutaneous thermoablation was collected and retrospectively analyzed. Complications, procedure related information and patient characteristics were collected from institutional records. Overall survival and disease-free survival were estimated using the Kaplan-Meier method.

* Correspondence: moritz.winkelmann@med.uni-tuebingen.de

'Department for Diagnostic and Interventional Radiology, University Hospital Tuebingen, Hoppe-Seyler-Straße 3, 72076 Tübingen, Germany

Full list of author information is available at the end of the article

(c) The Author(s). 2020 Open Access This article is licensed under a Creative Commons Attribution 4.0 International License, which permits use, sharing, adaptation, distribution and reproduction in any medium or format, as long as you give appropriate credit to the original author(s) and the source, provide a link to the Creative Commons licence, and indicate if changes were made. The images or other third party material in this article are included in the article's Creative Commons licence, unless indicated otherwise in a credit line to the material. If material is not included in the article's Creative Commons licence and your intended use is not permitted by statutory regulation or exceeds the permitted use, you will need to obtain permission directly from the copyright holder. To view a copy of this licence, visit http://creativecommons.org/licenses/by/4.0/ The Creative Commons Public Domain Dedication waiver (http://creativecommons.org/publicdomain/zero/1.0/) applies to the data made available in this article, unless otherwise stated in a credit line to the data. 
(Continued from previous page)

Results: A total of 31 patients (age: $62.8 \pm 9.1$ years; 10 female) with hepatocellular carcinoma $(H C C ; n=7)$ or hepatic metastases $(n=24)$ were treated for 98 hepatic tumors. Fifty-six tumors (mean diameter $28.7 \pm 23.0 \mathrm{~mm}$ ) were resected. Forty-two tumors $(15.1 \pm 7.6 \mathrm{~mm}$ ) were treated with MR-guided percutaneous ablation with a technical success rate of $100 \%$. Local recurrence at the ablation site occurred in 7 cases (22.6\%); none of these was an isolated local recurrence. Six of 17 patients (35.3\%) treated for colorectal liver metastases developed local recurrence. Five patients developed recurrence at the resection site (16.1\%). Non-local hepatic recurrence was observed in 18 cases (58.1\%) and extrahepatic recurrence in 11 cases (35.5\%) during follow-up (43.1 \pm 26.4 months). Ten patients (32.3\%) developed complications after HR requiring pharmacological or interventional treatment. No complication requiring therapy was observed after ablation. Median survival time was $44.0 \pm 7.5$ months with 1-,3-, 5-year overall survival rates of 93.5, 68.7 and 31.9\%, respectively. The 1-, 3- and 5-year disease-free survival rates were 38.7, 19.4 and $9.7 \%$, respectively.

Conclusion: The combination of HR and MR-guided thermoablation is a safe and effective approach in the treatment of technically unresectable hepatic tumors and can achieve long-term survival.

Keywords: MR-guided intervention, Radiofrequency ablation, Microwave ablation, Hepatic metastases, Hepatic resection, Combination therapy, Percutaneous thermoablation

\section{Background}

Hepatic resection is presently considered the gold standard in potentially curative treatment for patients with hepatic malignancies [1]. However, due to a variety of anatomical and pathological factors, many patients are not candidates for surgical resection, including 70-80\% of patients with colorectal liver metastases (CRLM) [2, $3]$. High hepatic tumor burden often precludes a curative resection due to insufficient remnant liver function [4]. In order to expand the benefits of hepatic resection to a greater number of patients, a range of strategies have been developed such as neoadjuvant chemotherapy, two-stage hepatectomy, preoperative portal vein embolization and combination of hepatic resection and thermoablation [5-8]. Several groups have reported that combined treatment using hepatectomy and thermoablation may achieve long-term survival rates which are comparable to hepatectomy alone [9-11]. The most common representatives of thermoablation techniques are radiofrequency ablation (RFA) and microwave ablation (MWA), with the latter gaining importance due to its technical advantages as higher intra-tumoral temperatures result in larger ablation zones in a shorter time [12]. MWA is also less susceptible to the heat sink effect, and has recently been reported to be associated with lower local-recurrence rates [13].

For thermoablation in a single procedure, the percutaneous approach is well established with most procedures being performed under CT- or ultrasound guidance [14]. MRI offers an alternative guidance modality, but is presently limited to a small number of specialized institutions. Despite this reduced prevalence, MR-guided procedures offers several clinically valuable advantages over other modalities, including near-real-time MR-fluoroscopy for accurate applicator placement, free selection of imaging planes, MR thermometry for precise delivery of thermal energy, enhanced sensitivity for small target lesions and peri-procedural assessment of the ablation process without requiring application of contrast agents [15-17].

The aim of this study was to investigate safety, survival and local recurrence rates for patients with technically unresectable liver tumors undergoing hepatectomy and separate percutaneous MR-guided thermoablation procedure as an alternative approach to hepatectomy with intraoperative ablation.

\section{Methods \\ Patient population}

All patients with liver tumors who received percutaneous thermoablation (RFA or MWA) between June 2004 and July 2018 at a single institution were retrospectively identified from an institutional database. Inclusion criteria included: 1) primary or secondary hepatic malignancy not amenable to hepatic resection alone as determined by an interdisciplinary institutional tumor board, 2) combination therapy using hepatic resection and percutaneous MR-guided thermoablation in a separate procedure, and 3) available follow up imaging. Patients were excluded if percutaneous thermoablation was conducted as therapy for recurrence after prior hepatic surgery, as only planned combination therapy was investigated in this study.

\section{Percutaneous ablation and surgical resection}

Treatment decisions were determined by an interdisciplinary tumor board consisting of representatives from the departments of surgery, internal medicine, radiology, pathology, nuclear medicine and radiotherapy. Decision criteria to determine appropriate therapy included tumor size, number of lesions, anticipated loss of functioning 
liver parenchyma, presence and degree of cirrhosis and overall state of health. Extent of hepatic resection, lesion assignment to thermoablation and chronological order of resection and ablation were defined in the interdisciplinary tumor board. Hepatic resection was classified according to Brisbane Classification as hemihepatectomy (right or left), sectionectomy (right anterior, right posterior, left medial, left lateral), trisectionectomy (right, left), segmentectomy, bisegmentectomy and atypical resection [18].

One ablation procedure was conducted in a C-shaped, open low-field 0.2 T MRI system (Magnetom Concerto, Siemens Healthineers, Erlangen, Germany). The further 30 procedures were consecutively conducted in a closed bore, whole-body 1.5 T MRI system (Magnetom Espree, Siemens Healthineers). All procedures were conducted in supine position with elevation of the right side if tumors in the right posterior segments were treated [19]. Local anesthesia was injected percutaneously at the puncture site and additional analgesia (piritramide or pethidine) and sedation (midazolam) were administered intravenously during the intervention. In cases of unfavorable tumor position (e.g. subcapsular tumor location), procedures were conducted using general anesthesia. A standardized planning MRI protocol with native sequences was used to confirm tumor number, size, and localization. If tumor visualization was impaired or further hepatic tumor manifestations were suspected, additional diffusion-weighted imaging sequences (DWI) and dynamic contrast-enhanced sequences were acquired after administration of extracellular contrast agent (Gadovist, Bayer HealthCare, Leverkusen, Germany) or hepatocyte-specific contrast agent (Primovist, Bayer HealthCare). Tumor targeting was conducted using steady-state free precession MR-fluoroscopic sequences (BEAT_IRTT) which continuously depicted the applicator path in three dimensions [20]. The interventionalist observed the applicator placement on an inroom LCD-Monitor installed next to the magnet. During thermoablation, the applicator was connected with an extended cable to the generator positioned outside the scanner room. T1- or T2-weighted sequences were used to assess the ablation result as reported in prior work [21]. In the event of an inadequate ablation zone or residual tumor tissue, additional ablation was conducted after repositioning the applicator under MR-fluoroscopy. When the safety margin around the tumor was considered sufficient, the applicator was retracted after tract coagulation. Post-interventional control examination using dynamic contrast-enhanced $\mathrm{T} 1$ sequences and a T2 sequence was used to assess the technical success and exclude complications such as hematomas, biliomas, intraperitoneal free fluid or active bleeding. Patients were routinely hospitalized for one night post-ablation and discharged if complete blood count and control ultrasound of the liver were found to be within acceptable limits [20].

\section{Data collection}

The local ethics committee approved the retrospective analysis of patient data. Data concerning demography, tumor entity and use of neo-adjuvant therapies were collected from the interdisciplinary tumor-board records. Tumor size and location were defined by measurements using pre-interventional multiphasic MR-images collected no more than 4 weeks prior to intervention. Complications, duration of hospitalization, administration and timing of systemic therapy, follow-up results and recurrence therapies were collected from institutional medical records and operative/interventional reports. Complications were classified according to the ClavienDindo classification [22].

Internal guidelines for follow-up after thermoablation include contrast-enhanced dynamic MRI of the liver 1 month post-procedure, every 3 months thereafter for 1 year and extended to every 6 months thereafter. For data analysis, length of follow-up was defined beginning at the date of the initial procedure and ending at the date of death for deceased patients or at the date of last follow-up visit for surviving patients.

\section{Statistical analysis}

Percentages and mean values were calculated and reported with associated standard deviations. Overall survival and disease-free survival were estimated using the Kaplan-Meier method. Survival data were calculated independently of the censored cases. Group-comparisons were conducted with Student's t-test. All statistical analysis was performed using SPSS (version 26.0; SPSS Inc., Chicago, IL). $P$-values $<0.05$ were considered statistically significant.

\section{Results}

\section{Patient and tumor characteristics}

A total of 535 patients with primary or metastatic liver tumors were treated with RFA or MWA. Of these, 103 patients underwent additional surgery. Patients who underwent either surgical resection or thermoablation due to a recurrence after intervention were excluded. A total of 32 patients underwent ablation and surgery in combination as recommended by the interdisciplinary tumor board. One patient was excluded due to a lack of follow-up data, resulting in 31 patients included for further analysis (Fig. 1). There were 21 men and 10 women with a median age of 62.8 years \pm 9.1 years. Of these 31 patients, 17 were patients with colorectal cancer liver metastases (CRLM) and seven with metastases from another tumor entity (Table 1). Seven patients were treated 
No. of participants: RFAMWA-

Interventions (June 2004-July 2018)

n (=535)

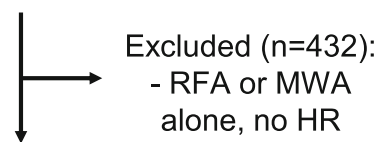

No. of patients with HR and RFAMWA

$(n=103)$

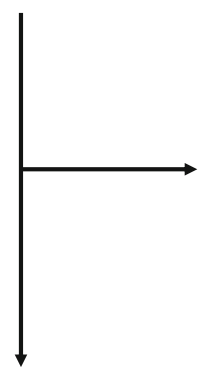

Excluded $(n=72)$ :

- treatment of recurrences

- no tumor board recommendations

- insufficient followup

HR and RFA/MWA combined in an multidisciplinary approach $(\mathbf{n = 3 1})$

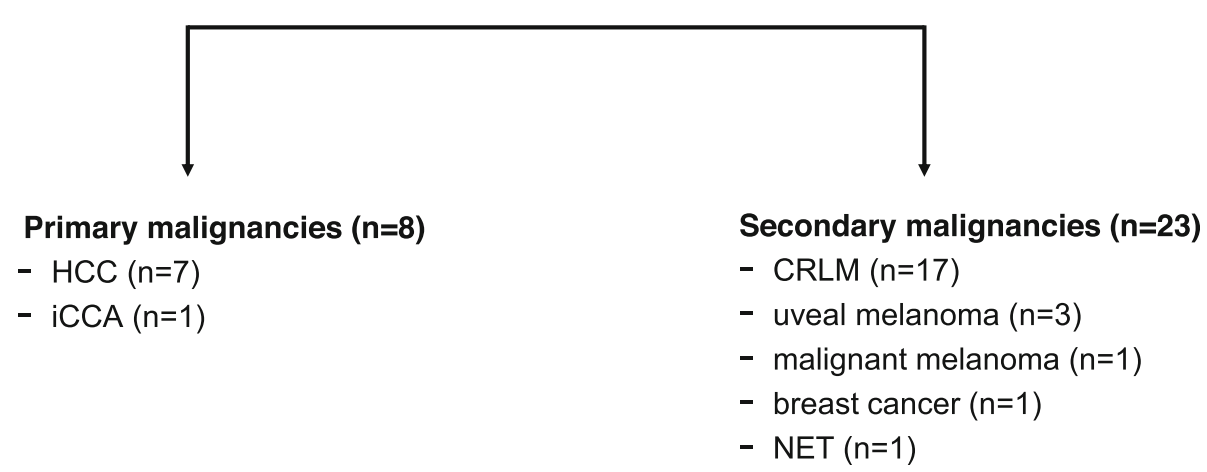

Fig. 1 Study flowchart. CRLM = colorectal liver metastases, HCC = hepatocellular carcinoma, iCCA = intrahepatic cholangiocarcinoma, NET= neuroendocrine tumor. Data is given in numbers ( $n$ )

for hepatocellular carcinoma (HCC). A total of 42 lesions with a mean tumor size of $15.1 \pm 7.6 \mathrm{~mm}$ (range: 4-35 mm) were treated with thermoablation. Twentythree patients underwent ablation of a single tumor, 6 patients of two tumors, one patient of three tumors and one patient of four tumors, respectively. Fifty-six lesions with a mean tumor diameter of $28.7 \pm 23.0 \mathrm{~mm}$ (range: 4-90 mm) were surgically resected. Hepatic resections were defined according to the Brisbane classification (Table 2) [18]. Fourteen patients had a single tumor resected, while 17 patients had several lesions resected in one setting ( 2 lesions in 9 patients and 3 lesions in 8 patients).

Fifteen of 17 patients treated for CRLM received neoadjuvant chemotherapy before combination therapy. Two patients with $\mathrm{HCC}$ received transarterial chemoembolization
(TACE) before the ablation procedure. In one patient with $\mathrm{HCC}$, combination therapy was conducted for bridging before liver transplantation, which was conducted 6 months after ablation.

\section{Procedures}

Radiofrequency ablation was performed in 24 patients and MWA in 7 patients. All procedures were conducted under MR-guidance and technical success was achieved in all ablation procedures. The average procedure duration including acquisition of planning sequences, applicator positioning (mean number of needle positions: $3.0 \pm 1.3$ ), therapy monitoring and post-interventional control imaging was $4.8 \mathrm{~h}$. Procedures with MWA were significantly faster than procedures with RFA (3.3 vs. $5.3 \pm 1.4 \mathrm{~h})(p<0.001)$. Fourteen patients received 
Table 1 Baseline characteristics

\begin{tabular}{|c|c|}
\hline Variables & $\mathrm{N}(\%) /$ mean $\pm \mathrm{SD}$ \\
\hline Age (years) & $62.8 \pm 9.1$ \\
\hline Patients & 31 \\
\hline $\operatorname{Sex}(m / f)$ & $21(67.8 \%) / 10(32.2 \%)$ \\
\hline Number of tumors (ablated/resected) & $98(42 / 56)$ \\
\hline Tumor size of ablated lesions & $15.1 \pm 7.6 \mathrm{~mm}$ \\
\hline Tumor size of resected lesions & $28.7 \pm 23.0 \mathrm{~mm}$ \\
\hline \multirow[t]{10}{*}{ Tumor entity } & $\operatorname{HCC}(n=7)$ \\
\hline & $\mathrm{iCCA}(n=1)$ \\
\hline & Metastases $(n=23)$ \\
\hline & Colorectal carcinoma $(n=17)$ \\
\hline & - Left sided $(n=13)$ \\
\hline & - Right sided $(n=4)$ \\
\hline & Uveal melanoma $(n=3)$ \\
\hline & Malignant melanoma $(n=1)$ \\
\hline & Breast cancer $(n=1)$ \\
\hline & Neuroendocrine tumor $(n=1)$ \\
\hline Concomitant liver cirrhosis & $\begin{array}{l}\text { 5/31 (16.1\%); } \\
\text { Child A: } n=3 \text {, Child B: } n=2\end{array}$ \\
\hline \multicolumn{2}{|l|}{ Liver function (serum levels): } \\
\hline GOT/GPT (U/I) & $45.2 \pm 39.0 / 47.5 \pm 43.7$ \\
\hline Bilirubin (mg/dl) & $0.6 \pm 0.3$ \\
\hline Quick-Test (\%) & $96.6 \pm 13.9$ \\
\hline
\end{tabular}

HCC Hepatocellular carcinoma, iCCA Intrahepatic cholangiocarcinoma, TACE Transarterial chemoembolization

thermoablation before surgical resection (mean interval $0.9 \pm 0.6$ months) and 17 patients received thermoablation after surgery (mean interval $2.0 \pm 3.1$ months). In one patient with hepatic metastases from a uveal melanoma, a peritoneal carcinosis was diagnosed during atypical hepatectomy; consequently, planned thermoablation was postponed and systemic therapy administered. After a positive response to chemotherapy, thermoablation

Table 2 Surgical procedures according to Brisbane classification [18]

\begin{tabular}{ll}
\hline Surgical procedures (liver segments) & $\mathrm{N}(\%)$ \\
\hline Right hemihepatectomy & $5(16.1 \%)$ \\
Left hemihepatectomy & $5(16.1 \%)$ \\
Left lateral sectionectomy & $1(3.2 \%)$ \\
Right trisectionectomy & $1(3.2 \%)$ \\
Segmentectomy & $3(9.7 \%)$ \\
Atypical resection & $9(29.0 \%)$ \\
Left hemihepatectomy + atypical resection & $3(9.7 \%)$ \\
Left lateral sectionectomy + atypical resection & $3(9.7 \%)$ \\
Left lateral sectionectomy + segmentectomy & $1(3.2 \%)$ \\
+ atypical resection & \\
\hline
\end{tabular}

was then conducted 13 months after the initial surgery. Excluding this case, the mean period between resection and ablation was $1.3 \pm 0.9$ months. In four patients, a total of six additional lesions were detected by intraprocedural planning imaging. These new lesions with mean diameter of $7.2 \pm 3.2 \mathrm{~mm}$ (range: $4-11 \mathrm{~mm}$ ) were ablated in the same procedure (Fig. 2a-e). Length of hospital stay after thermal ablation was $1.8 \pm 1.1$ days (range: $1-5$ days). Length of hospital stay after surgery was $12.8 \pm 6.2$ days (range: $7-37$ days).

\section{Complications}

Ten patients suffered complications after surgery. Grade 2 complications in which pharmacological treatment was necessary were observed in 6 patients and included ascites, capillary leak, infection, pneumonia and hypertension. One patient developed a hematoma of the abdominal wall which necessitated treatment without general anesthesia (Grade 3a). Following surgery, one patient had wound infection (Grade 3a). A subhepatic abscess was observed in two patients and re-laparotomy had to be performed (Grade 3b). No mortality has occurred.

No complications were observed after thermoablation. One patient developed acute conjunctivitis after RFA resulting in a post-interventional hospitalization period of 5 days; however, this event was determined not to be related to the thermoablation procedure.

\section{Recurrence}

Overall, recurrence was observed in 26 patients. One of seven patients (14.2\%) with HCC and 6/24 (25\%) with hepatic metastases (all treated for CRLM) developed local recurrence at the ablation site. Overall local recurrence rate at the ablation site was $22.6 \%$ on a perpatient-basis and $16.6 \%$ on a per-tumor-basis. Two of 6 patients (33\%) with local recurrence of a CRLM had a primary right-sided colon carcinoma. None of the patients with local recurrence at the ablation site developed an isolated local recurrence (one patient had additional recurrence at the resection margin, three patients had an extrahepatic recurrence and five patients developed new manifestations in the remaining liver). The mean diameter of the ablated tumors with local recurrence $(22.9 \pm 7.3 \mathrm{~mm})$ was significantly larger than in tumors without local recurrence $(13.2 \pm 6.0 \mathrm{~mm} ; p=$ 0.017). None of the patients treated with MWA developed local recurrence during follow-up.

Recurrences at the surgical resection site were observed in 5 patients $(16.1 \%$ on a per-patient-basis, $8.9 \%$ on a per-tumor-basis), including one patient with recurrence at both the resection area and the ablation zone. A total of 18 patients $(58.0 \%)$ developed non-local hepatic recurrences, and a total of 11 patients (35.5\%) were 

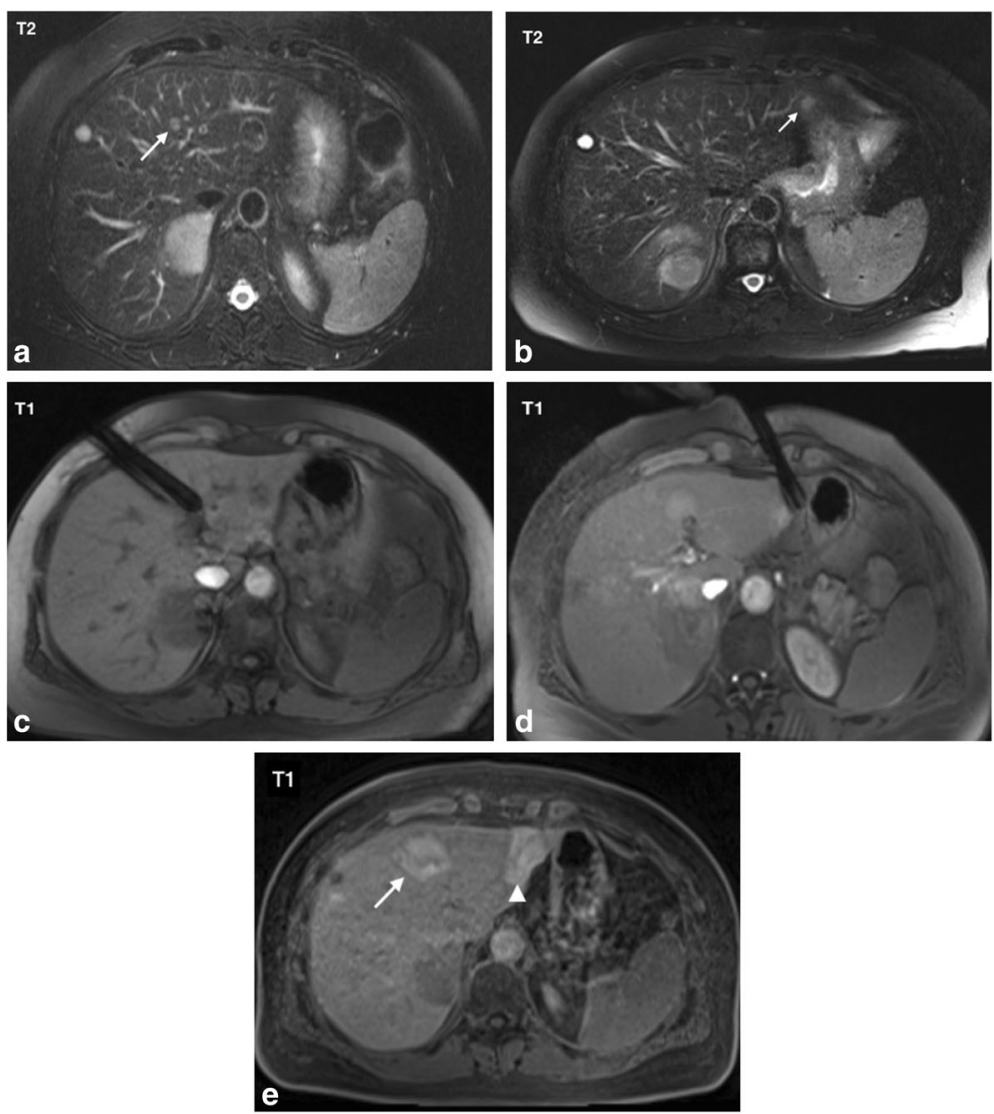

Fig. 2 62-year old female patient with hepatic metastases from a uveal melanoma in both liver lobes. According to tumor-board decision, right hemihepatectomy was planned after thermoablation of a metastasis in the left liver lobe. Pre-interventional T2-weighted TSE imaging (a) shows the target lesion planned for thermoablation. However, intra-procedural planning imaging (b) reveals a new small lesion subcapsular in segment 2 (arrow). Both tumors could be treated during the same procedure as depicted by intra-interventional T1-weighted sequences (c and $\mathbf{d}$ ) showing two radiofrequency antennas targeting both target tumors. T1-weighted control imaging shows the T1 hyperintense ablation zones covering both target tumors (e). Right hemihepatectomy was conducted 1 month after ablation

found to have extrahepatic recurrence during follow-up. During follow- up, nine patients underwent percutaneous thermoablation for 16 non-local recurrences and two patients underwent a second resection due to new hepatic tumors.Table 3 summarizes the cases with local recurrence at the ablation zone and the resection site and states the therapy after local recurrence. During follow- up, nine patients underwent percutaneous thermoablation for 16 non-local recurrences and two patients underwent a second resection due to new hepatic tumors.

\section{Survival}

The median length of follow-up was $43.1 \pm 26.4$ months. At the time of last follow-up, 11 patients were alive (five of those without evidence of disease), 18 patients died, and three were lost to follow-up. The median survival time was $44.0 \pm 7.5$ months and 1,3 , and 5 -year overall survival (OS) rates were 93.5, 68.7 and $31.9 \%$, respectively (Fig. 3). The median disease-free survival time was
$10.0 \pm 2.3$ months. The 1,3 , and 5-year disease-free survival rates after thermal ablation and hepatic resection were 38.7, 19.4 and 9.7\%, respectively (Fig. 4).

\section{Discussion}

The combination of surgical resection and thermoablation is a common approach to extend resectability in patients with hepatic malignancies. Several studies describe this approach, which employed a combination of resection and immediate intraoperative ablation [23, 24]. The approach described in this work differs in that percutaneous, MRguided thermoablation was conducted separately from the hepatic resection. Although the duration of hospitalization after percutaneous thermoablation was relatively short, this alternative approach is associated with a second procedure, and thus generally with a second hospitalization for the patient. Nevertheless, the motivation for this approach which has been conducted at our institution for over 10 years is based on the potential advantages of MRguided thermoablation. MRI-guided procedures offer high 
Table 3 Cases with local recurrence at the ablation zone and resection site including therapy after recurrence

\begin{tabular}{|c|c|c|c|c|c|}
\hline Case & Recurrence location & Target tumor & $\begin{array}{l}\text { Non-local recurrence } \\
\text { during follow-up }\end{array}$ & Initial Therapy after local recurrence & Further therapies during follow-up \\
\hline 1 & RS & $\mathrm{HCC}$ & yes & SIRT & Systemic therapy \\
\hline 2 & $A Z+R S$ & CRLM & yes & Systemic therapy & - \\
\hline 3 & RS & $\mathrm{HCC}$ & yes & Systemic therapy & - \\
\hline 4 & $A Z$ & CRLM & yes & SIRT & Systemic therapy \\
\hline 5 & $A Z$ & CRLM & yes & Systemic therapy & - \\
\hline 6 & $A Z$ & CRLM & yes & Hepatic resection & Systemic therapy \\
\hline 7 & $A Z$ & CRLM & yes & Thermal ablation & Thermal ablation \\
\hline 8 & $A Z$ & CRLM & yes & Thermal ablation & - \\
\hline 9 & RS & $\mathrm{HCC}$ & no & SIRT & Systemic therapy \\
\hline 10 & RS & CRLM & yes & Systemic therapy & - \\
\hline 11 & $A Z$ & $\mathrm{HCC}$ & yes & Thermal ablation & Thermal ablaton (2x) \\
\hline
\end{tabular}

AZ Ablation zone, RS Resection site, SIRT Selective internal radiation therapy, CRLM Colorectal liver metastases, HCC Hepatocellular carcinoma

soft tissue contrast and enables an immediate assessment of the ablation process without the administration of contrast medium, as the ablation zone can be seen as a T1 hyperintense area, whereas the target tumor is typically hypointense on T1 weighted imaging [21]. In contrast, with CT as a guidance modality, both the ablation zone and the target tumor appear hypodense in unenhanced imaging making a reliable differentiation between tumor and the ablation zone difficult [25]. Furthermore, the ablation process causes the formation of gas at the ablation zone, so that the assessment of the ablation process is challenging using ultrasound guidance [26]. MR fluoroscopy with free angulation of the imaging slices allows real- time monitoring and reconfiguration of applicator positioning, allowing tumors in challenging anatomical locations to be more safely reached [20,27]. The latter can be of particular relevance for the patients in our study if initial right-side hemihepatectomy causes a shift of the remaining left liver lobe so that the access is limited and applicator positioning is challenging. A further advantage of MRI as guidance modality is the high sensitivity in detection of small liver lesions [28]. Several studies have shown that MRI has a higher sensitivity in detection of small liver lesions in comparison to CT, so that preoperative acquisition of hepatic MRI can lead to a significant change in the treatment plan [29]. In four of our

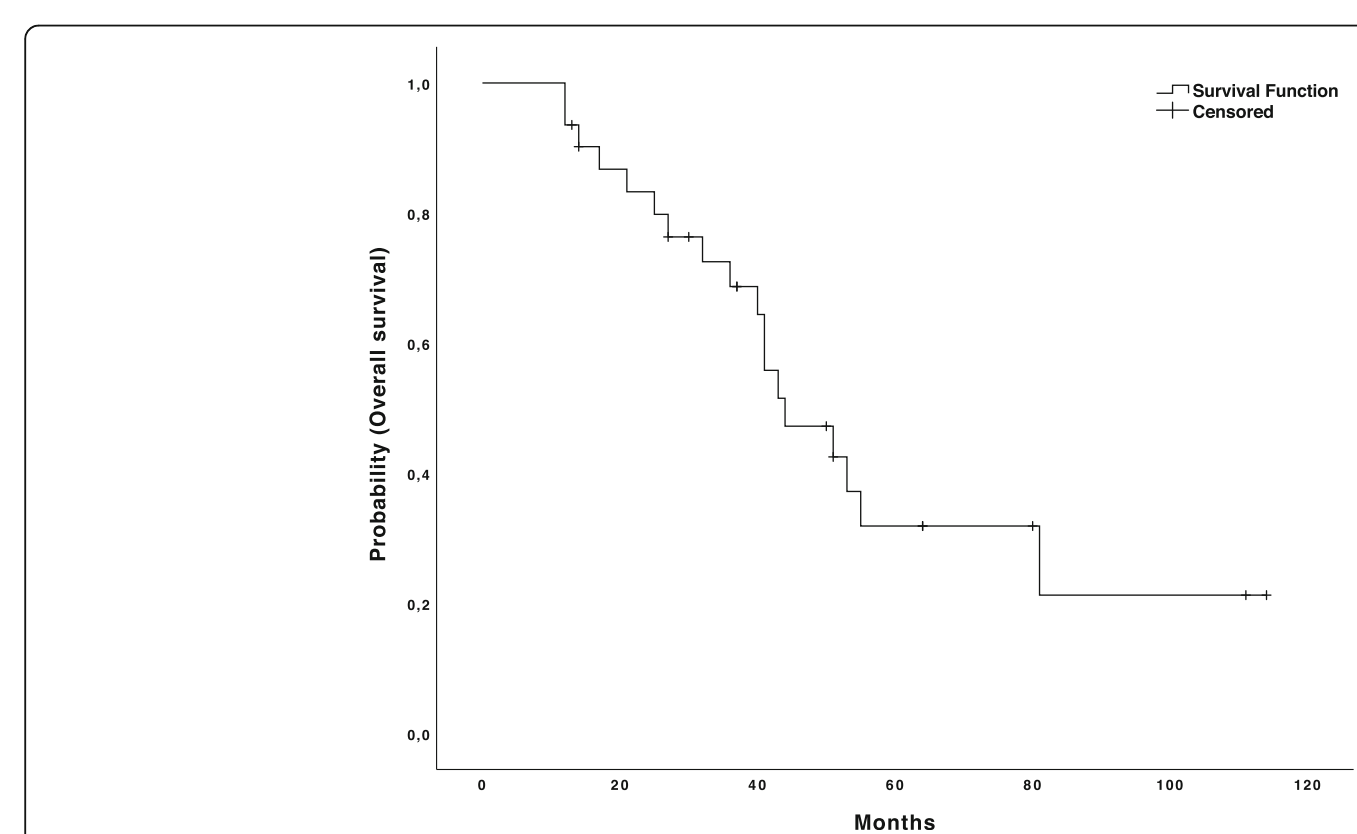

Fig. 3 The Kaplan-Meier overall survival curve. The Kaplan-Meier curve for overall survival after combined therapy. The starting point for calculation is the date of first treatment (ablation or resection) within the combined therapy 


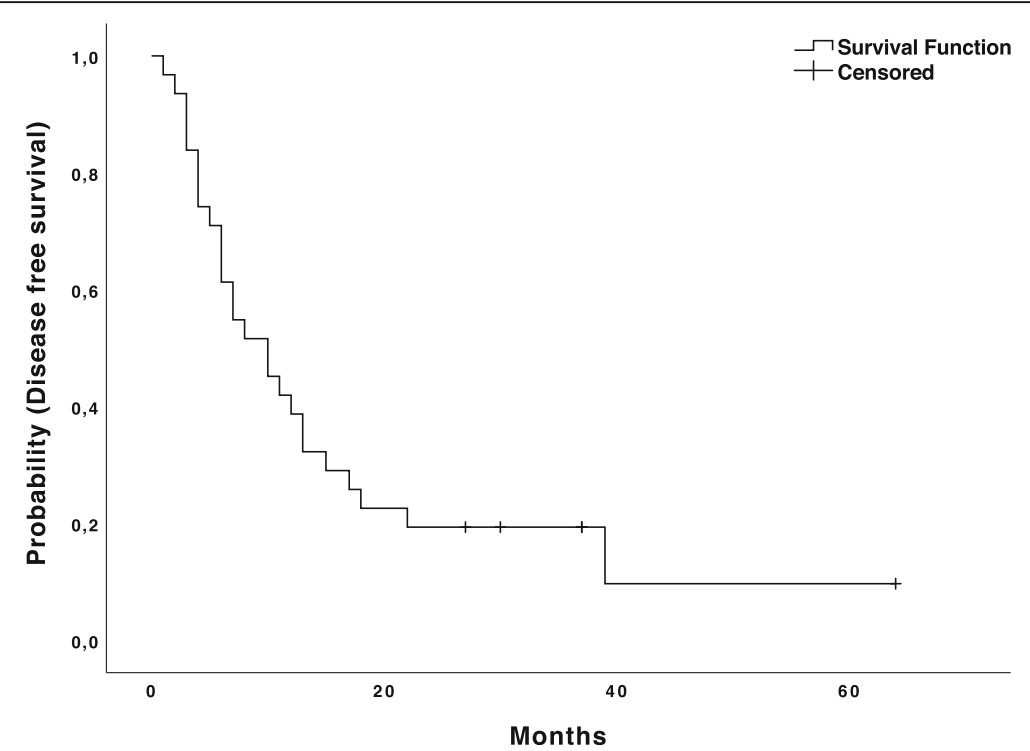

Fig. 4 The Kaplan-Meier disease-free survival curve. The Kaplan-Meier curve for disease-free survival after combined therapy. The starting point for calculation is the date of first treatment (ablation or resection) within the combined therapy

study patients, planning imaging at the beginning of the intervention revealed six new and therefore suspicious lesions, which could be successfully treated in the same procedure. Due to the small diameter of these new lesions ranging from 4 to $11 \mathrm{~mm}$, it is questionable if they would have been detected during planning imaging using other modalities. Despite these technical advantages of MRI as guidance modality, reduction of procedure durations is of particular interest to establish MR-guided thermoablation in clinical routine. In this context, MWA is a promising ablation technique as significantly shorter procedure durations can be achieved in comparison to RFA [13].

A comparison of the survival and recurrence data with earlier studies regarding resection combined with intraoperative thermoablation is difficult as available study results show heterogeneous cohorts and results. Qiu et al. reported the long-term outcome after hepatic resection and ultrasound-guided intraoperative radiofrequency ablation in 112 patients with HCC or hepatic metastases [30]. The 3 and 5-year survival rates in the HCC group were 32.5 and $12.5 \%$ and 50 and $19.4 \%$ in the group with liver metastases, respectively. Recurrence-free survival in the same study after 1 and 3 years in the HCC-Group was 52.5 and $22.5 \%$ respectively and 58.3 and $23.6 \%$ in the liver metastases group. Eisele et al. reported their results on 22 patients with primary and secondary hepatic malignancies who underwent hepatic resection combined with intraoperative radiofrequency ablation with a local recurrence rate at the ablation site of $32 \%$ on a per-patient basis. The 1 - and 3-years overall survival rate of this study was reported as 77 and $41 \%$, respectively [31]. Moreover, this study summarized the available literature and reported a high variation of overall survival rates ranging from 43 to $92 \%$ after 1 year. Although the survival rates in our study were above average, a relatively high local recurrence rate of $21.9 \%$ is striking. A previous study by Rempp et al. investigating MR-guided percutaneous RFA of primary and secondary liver tumors as a monotherapy showed a local recurrence rate of $8.6 \%$ [20]. As discussed by Sasaki et al., this effect may be explained by a selection bias, as patients undergoing combination therapy have different baseline characteristics compared to patients who undergo only one therapy, which may affect recurrence rates and observed outcome [11]. A potential indicator for unfavorable tumor characteristics in the patient cohort with local recurrence is the simultaneous high rate of non-local recurrence, as all patients with local recurrence developed new intra- or extrahepatic metastases. Furthermore, we observed an exceptionally high rate of local recurrence in the CRLM group (6 of 17 patients). Potential risk factors for local recurrence and poor oncological outcomes may include mutations such as BRAF and KRAS or right-sided colon cancer [32-34].

However, mutation analysis was not available in most cases of this retrospective study, so that an assessment of the effect of KRAS and BRAF mutations on local recurrence rates was not possible. Nevertheless, larger ablation zones with a larger safety margin should be achieved in this patient cohort, especially when larger tumors are treated.

The major limitations of this study are its retrospective design and the limited patient cohort with a high heterogeneity regarding tumor entities. Several factors which may have influenced the outcome, such as mutation 
status, could not be retrospectively collected. Furthermore, technical aspects such as the ablation technique may affect the ablation result but were not in the focus of this study due to the limited patient number.

\section{Conclusions}

In conclusion, the combination of hepatic resection and MR-guided thermoablation is a safe and effective approach in the treatment of technically unresectable hepatic tumors and can achieve long-term survival. MRguidance may have an effect on the course of treatment due to the high sensitivity regarding detection of small hepatic tumors. Nevertheless, larger prospective studies are necessary to evaluate the influence of tumor characteristics and ablation techniques on patient outcome.

\section{Supplementary information}

Supplementary information accompanies this paper at https://doi.org/10. 1186/s40644-020-00316-z

\section{Additional file 1}

\section{Abbreviations}

BRAF: V-raf murine sarcoma viral oncogene homolog B1; iCCA: Intrahepatic Cholangiocarcinoma; CRLM: Colorectal liver metastases; CT: Computed tomography; DWI: Diffusion-weighted imaging; HCC: Hepatocecellular carcinoma; HR: Hepatic resection; KRAS: Kirsten rat sarcoma viral oncogene homolog; LCD: Liquid crystal display; MRI: Magnetic resonance imaging; MWA: Microwave ablation; NET: Neuroendocrine tumor; OS: Overall survival; RFA: Radiofrequency ablation; SIRT: Selective internal radiation therapy; TACE: Transarterial chemoembolization; TSE: Turbo spin echo

\section{Acknowledgements}

Not applicable.

\section{Authors' contributions}

MW and RH conceptualized the study. MW, RH, RA, SN, JW, SC, GG and JK acquired and curated clinical data. MW and $\mathrm{RH}$ analyzed and interpreted the patient data. The manuscript was prepared by MW and $\mathrm{RH}$. KN, SN and GH edited and proof read the manuscript. All authors read and approved the final manuscript

\section{Funding}

The authors and their institutions have received no funding.

\section{Availability of data and materials}

A source data table is available.

\section{Ethics approval and consent to participate}

This retrospective study was approved by the Institutional Review Board of the University Hospital of Tuebingen and the requirement for informed consent was waived.

\section{Consent for publication}

Not applicable due to retrospective character of the study with full anonymization and waiver of informed consent by the local IRB.

\section{Competing interests}

The authors declare that they have no competing interests.

\section{Author details}

'Department for Diagnostic and Interventional Radiology, University Hospital Tuebingen, Hoppe-Seyler-Straße 3, 72076 Tübingen, Germany. ${ }^{2}$ Department of General, Visceral and Transplant Surgery, University Hospital Tuebingen,
Tübingen, Germany. ${ }^{3}$ Harvard Medical School, Harvard University, Boston, MA, USA.

Received: 19 March 2020 Accepted: 18 May 2020

Published online: 27 May 2020

References

1. Attwa MH, El-Etreby SA. Guide for diagnosis and treatment of hepatocellular carcinoma. World J Hepatol. 2015;7(12):1632-51.

2. Dorr NM, Bartels M, Morgul MH. Current treatment of colorectal liver metastasis as a chronic disease. Anticancer Res. 2020:40(1):1-7.

3. Adam R, Kitano Y. Multidisciplinary approach of liver metastases from colorectal cancer. Ann Gastroenterol Surg. 2019;3(1):50-6.

4. Schindl MJ, Redhead DN, Fearon KC, Garden OJ, Wigmore SJ. The value of residual liver volume as a predictor of hepatic dysfunction and infection after major liver resection. Gut. 2005;54(2):289-96.

5. Adam R, Miller R, Pitombo M, Wicherts DA, de Haas RJ, Bitsakou G, et al. Two-stage hepatectomy approach for initially unresectable colorectal hepatic metastases. Surg Oncol Clin N Am. 2007;16(3):525-36 viii.

6. Capussotti L, Muratore A, Mulas MM, Massucco P, Aglietta M. Neoadjuvant chemotherapy and resection for initially irresectable colorectal liver metastases. Br J Surg. 2006:93(8):1001-6.

7. Simoneau E, Hassanain M, Shaheen M, Aljiffry M, Molla N, Chaudhury P, et al. Portal vein embolization and its effect on tumour progression for colorectal cancer liver metastases. Br J Surg. 2015;102(10):1240-9.

8. Hompes D, Prevoo W, Ruers T. Radiofrequency ablation as a treatment tool for liver metastases of colorectal origin. Cancer Imaging. 2011;11(1):23-30.

9. Masuda T, Margonis GA, Andreatos N, Wang J, Warner S, Mirza MB, et al. Combined hepatic resection and radio-frequency ablation for patients with colorectal cancer liver metastasis: a viable option for patients with a large number of tumors. Anticancer Res. 2018;38(11):6353-60.

10. Imai K, Allard MA, Castro Benitez C, Vibert E, Sa Cunha A, Cherqui D, et al. Long-term outcomes of radiofrequency ablation combined with hepatectomy compared with hepatectomy alone for colorectal liver metastases. Br J Surg. 2017;104(5):570-9.

11. Sasaki K, Margonis GA, Andreatos N, Kim Y, Wilson A, Gani F, et al. Combined resection and RFA in colorectal liver metastases: stratification of long-term outcomes. J Surg Res. 2016;206(1):182-9.

12. Fan W, Li X, Zhang L, Jiang H, Zhang J. Comparison of microwave ablation and multipolar radiofrequency ablation in vivo using two internally cooled probes. AJR Am J Roentgenol. 2012;198(1):W46-50.

13. Takahashi H, Kahramangil B, Kose E, Berber E. A comparison of microwave thermosphere versus radiofrequency thermal ablation in the treatment of colorectal liver metastases. HPB. 2018;20(12):1157-62.

14. Puijk RS, Ruarus AH, Scheffer HJ, Vroomen L, van Tilborg A, de Vries JJ, et al. Percutaneous liver tumour ablation: image guidance, endpoint assessment, and quality control. Can Assoc Radiol J. 2018;69(1):51-62.

15. Wijlemans JW, Bartels LW, Deckers R, Ries M, Mali WPTM, Moonen CTW, et al. Magnetic resonance-guided high-intensity focused ultrasound (MRHIFU) ablation of liver tumours. Cancer Imaging. 2012;12(2):387-94.

16. Fischbach F, Lohfink K, Gaffke G, Wybranski C, Mohnike K, Wonneberger U, et al. Magnetic resonance-guided freehand radiofrequency ablation of malignant liver lesions: a new simplified and time-efficient approach using an interactive open magnetic resonance scan platform and hepatocytespecific contrast agent. Investig Radiol. 2013;48(6):422-8.

17. Salem U, Kumar VA, Madewell JE, Schomer DF, de Almeida Bastos DC, Zinn PO, et al. Neurosurgical applications of MRI guided laser interstitial thermal therapy (LITT). Cancer Imaging. 2019;19(1):65.

18. Strasberg SM. Nomenclature of hepatic anatomy and resections: a review of the Brisbane 2000 system. J Hepato-Biliary-Pancreat Surg. 2005;12(5):351-5.

19. Weiss J, Hoffmann R, Rempp $H$, Kebetaler DE, Pereira PL, Nikolaou K, et al. Feasibility, efficacy, and safety of percutaneous MR-guided ablation of small $(</=12 \mathrm{~mm})$ hepatic malignancies. J Magn Reson Imaging. 2019:49(2):374-81.

20. Rempp H, Waibel L, Hoffmann R, Claussen CD, Pereira PL, Clasen S. MRguided radiofrequency ablation using a wide-bore 1.5-T MR system: clinical results of 213 treated liver lesions. Eur Radiol. 2012;22(9):1972-82.

21. Rempp H, Unterberg J, Hoffmann R, Pereira PL, Schick F, Claussen CD, et al. Therapy monitoring of magnetic resonance-guided radiofrequency ablation using T1- and T2-weighted sequences at 1.5 T: reliability of estimated ablation zones. Investig Radiol. 2013;48(6):429-36. 
22. Clavien PA, Barkun J, de Oliveira ML, Vauthey JN, Dindo D, Schulick RD, et al. The Clavien-Dindo classification of surgical complications: five-year experience. Ann Surg. 2009;250(2):187-96.

23. Philips $P$, Scoggins CR, Rostas JK, McMasters KM, Martin RC. Safety and advantages of combined resection and microwave ablation in patients with bilobar hepatic malignancies. Int J Hyperth. 2017;33(1):43-50.

24. Zhang T, Zeng Y, Huang J, Liao M, Wu H. Combined resection with radiofrequency ablation for bilobar hepatocellular carcinoma: a single-center experience. J Surg Res. 2014;191(2):370-8.

25. Clasen S, Pereira PL. Magnetic resonance guidance for radiofrequency ablation of liver tumors. J Magn Reson Imaging. 2008;27(2):421-33.

26. Chiou S-Y, Liu J-B, Needleman L. Current status of sonographically guided radiofrequency ablation techniques. J Ultrasound Med. 2007;26(4):487-99.

27. Ricke J, Thormann M, Ludewig M, Jungnickel K, Grosser O, Wybranski C, et al. MR-guided liver tumor ablation employing open high-field 1.0T MRI for image-guided brachytherapy. Eur Radiol. 2010;20(8):1985-93.

28. Maegerlein C, Fingerle AA, Souvatzoglou M, Rummeny EJ, Holzapfel K. Detection of liver metastases in patients with adenocarcinomas of the gastrointestinal tract: comparison of (18)F-FDG PET/CT and MR imaging. Abdom Imaging. 2015;40(5):1213-22.

29. Riviere DM, van Geenen EJM, van der Kolk BM, Nagtegaal ID, Radema SA, van Laarhoven C, et al. Improving preoperative detection of synchronous liver metastases in pancreatic cancer with combined contrast-enhanced and diffusion-weighted MRI. Abdom Radiol (New York). 2019;44(5):1756-65.

30. Qiu J, Chen S, Wu H. Long-term outcomes after hepatic resection combined with radiofrequency ablation for initially unresectable multiple and bilobar liver malignancies. J Surg Res. 2014;188(1):14-20.

31. Eisele RM, Zhukowa J, Chopra S, Schmidt SC, Neumann U, Pratschke J, et al. Results of liver resection in combination with radiofrequency ablation for hepatic malignancies. Eur J Surg Oncol. 2010;36(3):269-74.

32. Tran B, Kopetz S, Tie J, Gibbs P, Jiang Z-Q, Lieu CH, et al. Impact of BRAF mutation and microsatellite instability on the pattern of metastatic spread and prognosis in metastatic colorectal cancer. Cancer. 2011;117(20):4623-32.

33. Odisio BC, Yamashita S, Huang SY, Harmoush S, Kopetz SE, Ahrar K, et al. Local tumour progression after percutaneous ablation of colorectal liver metastases according to RAS mutation status. Br I Surg. 2017;104(6):760-8.

34. Yahagi M, Okabayashi K, Hasegawa H, Tsuruta M, Kitagawa Y. The worse prognosis of right-sided compared with left-sided colon cancers: a systematic review and meta-analysis. J Gastrointest Surg. 2016;20(3):648-55.

\section{Publisher's Note}

Springer Nature remains neutral with regard to jurisdictional claims in published maps and institutional affiliations.

Ready to submit your research? Choose BMC and benefit from:

- fast, convenient online submission

- thorough peer review by experienced researchers in your field

- rapid publication on acceptance

- support for research data, including large and complex data types

- gold Open Access which fosters wider collaboration and increased citations

- maximum visibility for your research: over $100 \mathrm{M}$ website views per year

At $\mathrm{BMC}$, research is always in progress.

Learn more biomedcentral.com/submissions 